\title{
SignOS HEGEMÓNICOS EN EL FILME EX-MACHINA: ROBOTIZACIÓN Y CONTROL
}

\author{
Arturo Morales CAMpos* \\ Universidad Michoacana de San Nicolás de Hidalgo, México \\ arturo.morales@umich.mx
}

Recibido: 17/6/2020 Aceptado: 10/7/2020

DOI: https://doi.org/10.26439/contratexto2020.n034.4870

Resumen. El texto cinematográfico Ex-Machina (Garland, 2015), analizado bajo lineamientos sociosemióticos, presenta una serie de signos hegemónicos que remiten al fenómeno actual de la robotización del ser humano. Detrás de esa estrategia ficcional del filme, subyacen ideologías políticas y de mercado que se materializan en las propuestas conocidas como transhumanismo y biomejoramiento moral. En síntesis, parte de las investigaciones actuales dedicadas a aumentar las capacidades humanas se dirige hacia una nueva y más honda división darwinista social: por un lado, la atractiva posibilidad de superar el "obsoleto" cuerpo humano; por el otro, la promoción de fármacos que produzcan seres cada vez más dóciles y "éticos".

Palabras clave: signo hegemónico / texto / ideología / transhumanismo / biomejoramiento ético

\section{HEGEMONIC SIGNS IN THE FILM EX-MACHINA: ROBOTIZATION AND CONTROL}

Abstract. Based on social semiotics, the film Ex-Machina (Garland, 2015) presents some hegemonic signs that address the ongoing human robotization phenomenon. Behind such fictional strategy of the film underlie political and commercial ideologies that are materialized in two proposals known as transhumanism and moral bioenhancement. In short, part of current research devoted to increasing human capacities is directed towards a new and deeper social division of Darwinism: on the one hand, the attractive possibility of overcoming the "obsolete" human body; on the other, the promotion of drugs that generate increasingly docile and "ethical" humans.

Keywords: hegemonic sign / text / ideology / transhumanism / moral bioenhancement

\footnotetext{
* Doctor en Filosofía por la Universidad Michoacana de San Nicolás de Hidalgo, México (véase https://orcid. org/0000-0003-0939-8011).
} 


\section{SINAIS HEGEMÔNICOS NO FILME EX-MACHINA: ROBOTIZAÇÃO E CONTROLE}

Resumo. 0 filme Ex-Machina (Garland, 2015), analisado sob diretrizes socio-semióticas, apresenta uma série de sinais hegemônicos que se referem ao atual fenômeno de robotização do ser humano. Por trás dessa estratégia ficcional do filme, encontramos ideologias políticas e de mercado que se materializam nas propostas conhecidas como transhumanismo e biomelhoramento moral. Em conclusão, parte das pesquisas atuais dedicadas ao aumento das capacidades humanas é direcionada a uma nova e mais profunda divisão social de natureza darwiniana: por um lado, a possibilidade atraente de superar o corpo humano "obsoleto"; por outro, a promoção de fármacos que produzem pessoas cada vez mais dóceis e "éticas".

Palavras-chave: sinal hegemônico / texto / ideologia / transhumanismo /melhoramento moral 


\section{INTRODUCCIÓN}

La ciencia ficción, en forma general, plantea dos vías para la humanidad: un futuro pleno de comodidades o un futuro apocalíptico. "El contradictorio temor por un lado y por otro, la esperanza de mejora o la inmortalidad del ser humano, aspecto buscado desde siempre por diferentes culturas de forma histórica y que forma parte de numerosos mitos, creencias e imaginarios colectivos" (García-Sedano, 2019, p. 645). Aunque irreconciliables, esas vías tienen como raíz aspectos ontológicos y epistemológicos. Ontológicos, por la tendencia que va desde la visión de la máquina como herramienta hasta la máquina no solo como prótesis, sino como sustituto del ser humano. La búsqueda de mecanismos que superen, en eficiencia y capacidad, a la mente humana se relaciona con los aspectos epistemológicos. Ambas líneas no pueden quedar al margen de repercusiones éticas y manipulaciones políticas, como veremos. El cine de ciencia ficción ha resultado una especie de ventana que, a pesar de esa misma esencia ficcional, llega a cuestionar las problemáticas anteriores.

En este artículo, analizaremos el filme Ex-Machina (2015) del director británico Alex Garland. Creemos que, con una teoría sociosemiótica, es factible encontrar la reproducción de una ideología cuyas estrategias centrales son controlar y manipular en forma más eficiente a la sociedad actual. El transhumanismo y el biomejoramiento moral son dos herramientas tecnocomerciales que sustentan esa ideología.

Este trabajo está dividido en siete apartados. En el primero, mostramos algunas de nuestras bases teóricas y, en el segundo, exponemos elementos estructurales del texto cinematográfico. Los tres siguientes abordan nociones (signos hegemónicos) que contienen materia significante altamente determinante, a tal grado que permite una comprensión del sentido general del mismo texto. El sexto lo reservamos para el análisis de un par de intertextos. El último se concentra en revisar parte del trasfondo ideológico del transhumanismo y del biomejoramiento moral.

\section{SIGNOS HEGEMÓNICOS}

El texto, sin importar el código o códigos que lo compongan, presenta un ordenamiento sígnico específico. En un primer momento, este ordenamiento alude a la existencia de una estructura, la cual lo determina como un elemento de índole formal. En segundo lugar, los signos contenidos en ese texto establecen entre sí una sólida red. Esta fuerte imbricación refiere un funcionamiento, un sistema. Dentro de este nivel complementario, es factible encontrar sentidos textuales (específicos y/o generales) que reconocemos como procesos cognitivos. La división entre forma y fondo que hemos hecho es solamente para marcar pasos metodológicos y no es tajante en lo absoluto. 
Dado el elevado número de signos que pueden tener los diferentes textos, resulta casi imposible analizarlos todos. Ahora bien, existen jerarquías entre signos: algunos contienen mayor materia significante que otros. Aquellos de mayor densidad recibirán el nombre de signos hegemónicos. Su análisis resulta muy pertinente porque, en principio, contienen parte del sentido general del texto que los aloja. La alta capacidad semántica' atrae otros signos iguales o de menor jerarquía ubicados en otros espacios. Este proceder evita realizar un trabajo reduccionista, pues recordemos que los signos mantienen una estrecha interrelación. Este fundamento nos habla de una solidaridad sígnica². Finalmente, el análisis de esos signos nos permite acceder a connotaciones o funciones igualmente hegemónicas. Al respecto, queremos hacer una observación.

De acuerdo con el modelo triádico del signo de Charles Peirce (1994, p. 130), un interpretante puede ser el signo de otro nuevo proceso de semiosis. Umberto Eco (2000) parte de esta hipótesis para explicar la semiosis ilimitada:

La fertilidad de esta categoría [el interpretante] viene dada por el hecho de que se nos muestra que la significación (y la comunicación), mediante desplazamientos continuos, que refieren un signo a otros signos o a otras cadenas de signos, circunscriben las unidades culturales de modo asintótico, sin llegar a tocarlas directamente, pero volviéndolas de hecho accesibles a través de otras unidades culturales. (pp. 117-118)

En este marco, podemos decir que una connotación es el resultado de un proceso sígnico determinado (semiosis) y, por lo tanto, un interpretante susceptible de insertarse en otra "cadena" de signos. Esto nos sirve para establecer un paralelismo entre signos, connotaciones y funciones sígnicas, todos ellos hegemónicos ${ }^{3}$.

Hasta aquí, estamos en un nivel de análisis intratextual; es necesario, pues, pasar al nivel extratextual, en el que participa la sociosemiótica.

Todo texto emerge dentro de unas circunstancias sociohistóricas que, de alguna manera, lo circundan. Así, ese elemento cultural tiene la capacidad de reproducir parte de esas circunstancias, no de forma directa, sino mediada: el texto impone sus propias reglas y, digamos, "metaforiza" algo de la realidad social en la que se produce (véase Cros, 1986, 2002). Esta posición nos aleja de presunciones, un tanto ingenuas, que postulan una igualdad directa o natural entre la realidad que propone el texto y la realidad sociohistórica de la que emerge. El punto de unión entre este nivel extratextual y el intratextual residirá en los signos hegemónicos mencionados.

1 Utilizamos el término semántica, propio de la lingüística; no obstante, en nuestro análisis, puede estar vinculado a otros códigos diferentes.

2 A lo largo del trabajo, se entenderá esta solidaridad sígnica.

3 De hecho, Eco (2000, p. 46) marca una similitud entre signo y función sígnica. 


\section{LA DIÉGESIS DEL FILME}

La diégesis o historia se desarrolla dentro de una casa-laboratorio enclavada en un bosque de Alaska. Ese edificio se distingue principalmente por su alta seguridad y su lejanía de todo contacto humano ajeno. A través del uso de una llave digital, un sistema electrónico de seguridad abre o cierra todas las puertas; además, una red de cámaras cubre todas las áreas del edificio. Nathan, dueño de dicho complejo arquitectónico y fundador de la empresa que coordina un poderoso buscador en internet, llamado Blue Book, es quien, desde una computadora, controla ambos sistemas. En ese recinto, desarrolla un ambicioso proyecto de diseño de robots ginoides que poseen una alta inteligencia artificial.

Caleb es un joven empleado de Nathan. Ese chico resultó ganador en un concurso interno de la empresa para llevar a cabo un experimento, que consiste en entablar conversaciones con una robot llamada Ava, la última invención de Nathan. El ejercicio durará siete días en la casa-laboratorio, así que Caleb deberá participar en una sesión por día. Entre Ava y Caleb siempre existe un cristal de por medio, es decir, no tienen contacto físico directo. Nathan, en todo momento, monitorea las acciones de ambos, aun fuera de las sesiones. Antes de iniciar la investigación, Caleb debe firmar un contrato que restringe la divulgación de la información obtenida.

De acuerdo con el test de Turing, la intención es determinar si al final Caleb está convencido de que Ava es una máquina o una persona. En una de las primeras sesiones, Ava empieza a seducir a Caleb y, en consecuencia, llega a controlarlo. Ella tiene la intención de usar al chico para liberarse del enclaustramiento en el que la ha confinado Nathan y escapar de ahí. A partir del segundo encuentro, la robot provoca cortes breves de energía. Así, la pareja puede hablar con confianza, sin Nathan como intruso visual. Después de un plan fallido de Caleb para fugarse con Ava, esta logra desbloquear el sistema de seguridad general; con ayuda de Kyoko (otra ginoide que ofrece servicios sexuales y domésticos a Nathan), mata a su autor. Caleb termina atrapado en el edificio. Kyoko, a consecuencia de la lucha, queda desactivada. Como conclusión, Ava se disfraza de humana y viaja a la ciudad.

\section{JUEGO DE ESPEJOS}

En este apartado, a partir de lo que aparece en el plano de la expresión, abordaremos dos signos constantes y fundamentales en la diégesis, a saber, cristal y espejo para, posteriormente, arribar a las connotaciones que convocan.

La primera escena del filme nos presenta una imagen del ambiente interior de las oficinas en las que labora Caleb, a través de un cristal. Un poco después, se muestra a este chico, frente a su computadora, en el momento en que recibe la noticia de haber resultado triunfador. 
El edificio donde vive Nathan tiene tres niveles. El superior es la entrada y está situado directamente frente al bosque. Detrás de la puerta principal, hay un pasillo que conduce a la sala. Ese pasillo, de dimensiones un tanto estrechas, está formado por una estructura metálica y grandes cristales. La sala, la cocina y el comedor, ubicados en un segundo nivel inferior, poseen amplias ventanas hacia el exterior. Estos tres últimos espacios están conectados a una terraza al aire libre. El tercer nivel, más profundo, carece de ventanas y solo hay recintos de laboratorio, una sala de sonido, la recámara de Caleb, el pequeño cuarto de Ava, etcétera. La puerta de acceso a cada una de esas áreas es de un cristal blancuzco que no permite la visibilidad en ninguna dirección. Nathan (Garland, 2015, 0:08:20) hace notar a Caleb la ausencia de ventanas en ese piso, pues se trata de un "centro de investigación".

El resto de las ventanas representa un límite entre el exterior boscoso y el interior moderno, lujoso y minimalista del edificio. A pesar de que la transparencia de los cristales permite una idea de continuidad entre ambos ambientes, el contraste de espacios es tan marcado que resalta el carácter fronterizo. De hecho, el primer encuentro entre ambos (Garland, 2015, 0:05:32) se da a través de una de las ventanas de la cocina: Nathan está haciendo ejercicio en la terraza y Caleb, ansioso, logra verlo a la distancia, gracias al amplio ventanal.

Las sesiones que Caleb lleva a cabo con Ava se registran en un recinto con una división principal: a un lado de una pequeña sala, se coloca Caleb; del otro, en un cuarto también de dimensiones reducidas y con algunas secciones, aparece Ava. De por medio, como dijimos, siempre estará un cristal. Veamos otras funciones de este signo redundante en la trama.

La transparencia del cristal que separa a Caleb y a Ava remite a otras lecturas semánticas. La sesión inaugural (Garland, 2015, 0:11:25) se trata también de un primer encuentro, similar al anterior, es decir, a través de un cristal y, durante los primeros instantes, con la misma formalidad de la presentación y el nerviosismo de Caleb, además de su extrañamiento evidente.

El chico entra en la estancia, se acerca al grueso cristal divisorio y lo golpea suavemente con los nudillos para comprobar su solidez. Posteriormente, advierte que hay una parte estrellada. Al fondo, percibe la imagen de Ava mediante el reflejo en dos cristales del cuarto de la robot. Ella, lentamente, se aproxima a Caleb y es quien empieza el diálogo con un saludo. Durante todo este evento, el reflejo de ambos puede verse desde varios puntos y en diferentes cristales. Asimismo, se mezclan escenas de Nathan quien, ubicado en otra habitación, los observa por tres pantallas de su computadora.

El diálogo resulta simple al inicio. Un poco después de esto, Ava dice no haber conocido a otra persona después de Nathan. Caleb responde: "Entonces, supongo que eso nos coloca en una situación similar". Él se refiere a que nunca había estado frente a un robot como ella. 
Finalizada esa sesión, la escena posterior (Garland, 2015, 0:15:15) se registra en la cocina. Caleb está de espaldas al gran ventanal y expresa su emoción por la experiencia a Nathan: "[Ava] es fascinante. Cuando hablas con ella, estás justo a través del cristal". Queremos subrayar que, en inglés, Caleb usa la palabra looking glass, cuya traducción es "espejo" o "cristal"4.

Notemos, pues, la importancia del objeto cristal (visual, oral y somatosensorialmente) del que devienen los signos que nos interesan. Su importancia y reiteración pueden convocar funciones torales para nuestro trabajo.

Para comenzar, pongamos atención en la oración de Caleb: "Entonces, supongo que eso nos coloca en una situación similar". Si la relacionamos con la última: "Cuando hablas con ella, estás justo a través del espejo" (como en el idioma original), encontramos un sentido diferente. Sabemos que Caleb, en la primera, establece un paralelismo entre Ava y él en cuanto a la situación de no conocer a alguien más. Para Ava, esto es: otra persona, además de Nathan; para Caleb, un robot como Ava. En la segunda oración, el concepto espejo adquiere una lectura que connota el "enfrentamiento con una (id)entidad humana": "atravesar el espejo" equivale a "estar con una persona de verdad y, por lo tanto, no ver un simple reflejo, sino traspasar la frontera especular". Por lo tanto, la referencia de Caleb, "eso nos coloca en una situación similar", se distancia del sentido literal para abordar nociones de igualdad identitaria; es decir, no hay una frontera, ni física ni esencial, entre él y ella.

En conclusión, una de las funciones de los cristales es "mirar más allá de lo inmediato" o, concretamente, "mirar una id-entidad humana", muy a pesar de que, a la vez, signifique "frontera". De acuerdo con Eco (2000), "UN SIGNO NO ES UNA ENTIDAD SEMIÓTICA FIJA" (p. 84; el resaltado es textual); así, un mismo signo, dentro de un mismo texto, puede tener más de un sentido. En nuestro caso, esos sentidos no se contraponen irreconciliablemente, sino que, como veremos, guardan cierta complementariedad.

\section{MUNDO VIGILADO}

Ahora, veamos que las funciones del cristal o del espejo, colocadas en otro contexto y otras circunstancias, se resemantizarán para generar connotaciones adicionales. Como queda claro, la función más elemental de esos dos elementos mencionados es, simplemente, "mirar" o "ver".

4 El término looking glass ya es una forma un tanto anticuada frente a mirror. Más adelante, abordaremos las implicaciones intertextuales de dicho concepto.

5 La separación del prefijo id-cobrará mayor sentido más adelante. 
Sabemos de la existencia del circuito cerrado que Nathan instaló en el edificio, y que controla desde una computadora con tres pantallas. Por ese conjunto de artefactos, tiene la posibilidad, además, de examinar otros espacios. Por un lado, queda claro y justificado que Nathan observe cada una de las sesiones, ya que, como diseñador de Ava y del experimento, debe tomar notas e, incluso, preguntarle a Caleb sus impresiones después de las entrevistas, así como algo no menos importante: asegurarse de que el chico no se salga de las reglas del contrato.

Por otro lado, frente a la cama de Caleb, hay una pantalla conectada a varias de las cámaras instaladas alrededor del cuarto de Ava. De esta manera, él puede apreciarla o, en todo caso, estudiarla cuando no está con ella. En la madrugada del primer día, Caleb despierta y enciende esa pantalla (Garland, 2015, 0:18:20). Puede ver cómo Ava toca un identificador electrónico de acceso con la palma de la mano. De inmediato, se produce un corte general de electricidad. Caleb, ansioso, se percata de que la puerta de su cuarto está bloqueada. Este "accidente" será una estrategia de Ava para que, cuando ella y Caleb se encuentren de nuevo, puedan hablar sin que Nathan lo sepa, ya que las cámaras también estarán desactivadas. Desde la segunda sesión (Garland, 2015, 0:25:45), Ava ocasiona esos cortes para trazar con el chico los puntos de su plan. Segundos antes de la primera interrupción de energía, ella le pregunta al joven si le agrada Nathan, de inmediato aparecen dos tomas que enfocan, correspondientemente, cada una de las cámaras situadas en ese espacio. Durante el corte, Ava le confiesa a Caleb lo que piensa de Nathan; le advierte que no debe confiar en él, que no debe considerarlo su amigo. Esta situación es la que provoca un cambio semántico en las marcas connotativas elementales "mirar" y "observar"; a saber, se transforman en "vigilar". Expliquemos.

Después de esa sesión (Garland, 2015, 0:33:42) y durante la cena, Nathan le pregunta a Caleb acerca de su reunión con Ava ese día. El diálogo se torna difícil cuando Nathan toca el tema de la suspensión de corriente. Quiere saber qué hablaron en ese instante. Caleb, un tanto nervioso, simplemente contesta que no ocurrió cosa alguna. Nathan, con dificultad, acepta esa respuesta. Desde ese momento, la sospecha cubre gran parte de la diégesis y las acciones de vigilancia determinarán a los tres personajes.

Existe un antecedente de esta acción. En las escenas iniciales, cuando Caleb recibe el correo que le informa ser el ganador del concurso para participar en el experimento, hay diversas tomas en las que las dos pantallas y la cámara de su computadora parecen registrar los movimientos del chico. Caleb, con claras señales de alegría, manda mensajes en el celular para compartir la noticia con algunas de sus colegas. Hay tres fugaces efectos que indican la función "vigilancia": un efecto técnico nos sugiere que percibimos el rostro de Caleb desde ese par de pantallas; un acercamiento toma la cámara de la computadora en funcionamiento, dirigida al mismo chico; un conjunto de haces de luces coloridas registra cada uno de sus gestos, a manera de escáner. 
En otro momento, antes de la tercera sesión (Garland, 2015, 0:36:29), Nathan invita a Caleb al laboratorio donde ha creado a Ava (además de los proyectos robóticos antecedentes). Le confiesa al chico que lo más difícil del diseño fue hacerse de una inteligencia artificial que le permitiera a Ava leer y reproducir las expresiones faciales de las personas. La manera de resolverlo se dio mediante el uso de su buscador, el Blue Book:

Nathan: Cada celular, de estos tiempos, tiene un micrófono, una cámara y medios para transmitir datos. Así que dirigí los micrófonos y las cámaras de todo el maldito planeta y redireccioné los datos a través de Blue Book. ¡Bum! Recursos ilimitados de interacciones faciales y vocales.

Caleb (intrigado): ¿Hackeaste todos los celulares del planeta?

Nathan: Sí. Y todos los fabricantes sabían que lo hacía, pero no podían acusarme sin admitir que ellos también lo estaban haciendo.

Notemos que las últimas líneas de Nathan refieren, aunque con objetivos más bien comerciales, un mundo bajo constante vigilancia.

Finalmente, durante la penúltima sesión (Garland, 2015, 1:15:34), Caleb, ya completamente convencido de la información de Ava, planea con ella el escape que se dará esa misma noche. A la hora del almuerzo, Nathan y Caleb sostienen una plática que va subiendo de tono. Caleb trata de emborrachar a Nathan para quitarle la llave maestra, pero este se niega, pues quiere desintoxicarse.

El día previo, Nathan había bebido demasiado y se quedó dormido. Caleb aprovechó para quitarle la llave maestra. Utilizó su computadora y revisó unos videos en los que se muestran procesos de construcción de los otros especímenes robóticos. Esas máquinas, ya abandonadas, sirvieron para perfeccionar a Ava. Nathan siguió el mismo diseño físico y vació en el cerebro de Ava toda la información que recopiló de las demás ginoides. Anteriormente, Nathan (Garland, 2015, 1:05:20) le había explicado a Caleb este procedimiento "evolutivo" de sus creaciones. Este último se siente muy molesto, pues adivina que Ava terminará desconectada algún día. En uno de esos videos, una robot, Jade, le cuestiona duramente a Nathan el encierro; desesperada, golpea el cristal y lo estrella. Esta señal es la que nota Caleb en el primer encuentro con Ava. Su relación sentimental con la robot lo coloca en circunstancias diferentes a las del experimento: relaciona a Ava con el "sufrimiento" de Jade y, lo más grave, predice la irremediable suspensión de Ava, que representaría la "muerte" de esa máquina.

Ya de regreso en su cuarto (Garland, 2015, 1:13:50), Caleb se mira en el espejo. Podemos percibirlo desde esa perspectiva, es decir, desde el espejo. De nuevo, como al inicio del filme, un haz de luces de colores escanea su rostro. En esta escena, Caleb se hace un corte en el brazo para comprobar si es humano o robot (abordaremos este 
hecho en el próximo apartado). Cuando discuten, Nathan le dice al chico que vio cómo se hacía daño.

Nathan no olvida que las suspensiones de energía le impiden saber qué pasa entre la ginoide y el chico a lo largo de esos períodos; así, en algún momento, instala una cámara de baterías en el cuarto de Ava. En el almuerzo antes mencionado, le muestra a Caleb el video en el que la pareja urdía el plan. Para Nathan, esa es una prueba de que el experimento fue un éxito. Con el fin de calmarlo y convencerlo de su buena participación, Nathan le revela la verdad al joven.

Caleb: ¿Cuál era el verdadero test?

Nathan: Tú... Ava era una rata en una caja y le di una sola salida. Para escapar, ella debía usar su conciencia, imaginación, manipulación, sexualidad, empatía. Y lo hizo. Si eso no es inteligencia artificial, ¡¿qué carajos es?!

Caleb: Entonces, ¿mi única función fue ser alguien que ella usara como medio de escape?

Nathan: Sí.

Caleb: ¿No me seleccionaste por ser buen programador?

Nathan: No. [...]

Caleb: Me seleccionaste basándote en mis búsquedas.

Nathan: Me mostraron un buen chico.

Caleb: Sin una familia.

Nathan: Con una brújula moral.

Caleb: Sin una novia [...]. ¿Diseñaste la cara de Ava a partir de mis gustos de pornografía?

Debemos advertir algunas cosas. A pesar de la intromisión de Nathan en la vida privada de Caleb y de las acciones de jaqueo, obró con honestidad dentro del experimento; en este sentido, su función de "vigilante" se reduce a la de "observador científico". Empero, desde la perspectiva de Caleb, debido a su grado de involucramiento sentimental con Ava, esa misma función es la que distingue a Nathan como un personaje vigilante, coercitivo y "deshumanizado".

El circuito cerrado, el sistema de seguridad, la separación del edificio y el enclaustramiento, casi carcelario, nos remiten a la estructura arquitectónica de Jeremy Bentham 
(1748-1832) llamada panóptico ${ }^{6}$. Estos elementos extra coadyuvan en la consolidación de la connotación "vigilancia".

\section{SIMULACIÓN}

La simulación es una característica común y una meta de la inteligencia artificial, al igual que para el diseño de robots. En nuestro texto, esta propiedad destaca a Ava (y al resto de las creaciones de Nathan) a tal grado que Caleb humaniza a la ginoide: la cree capaz de manifestar sentimientos y deseos, es decir, de ser poseedora de conciencia. La seducción es una de las funciones que le permiten a Ava lograr el engaño.

Al final de la primera sesión, la robot le pregunta a Caleb si regresará al día siguiente. Ante la respuesta afirmativa del chico, ella muestra una breve, pero efectiva, sonrisa. Esto no nos debe resultar trivial, puesto que un robot no experimenta emociones. No obstante esto, ese gesto es el inicio de la paulatina atracción que sentirá Caleb por Ava.

La apariencia física externa de la robot es muy similar a la de un humano, excepto por algunas partes evidentemente artificiales. El rostro, las manos y los pies son de una persona. A su vez, la cara presenta rasgos finos y un tanto infantiles. El resto de la cabeza, el cuello, el vientre y las piernas, aunque mantienen una figura femenina, están compuestos por una especie de plástico transparente que permite apreciar cables y otros elementos electrónicos en su interior. El pecho, la parte de la espalda a esa altura y la zona de las caderas (por ambos lados) están fabricados de un material gris no traslúcido. De no ser por estas excepciones robóticas, el cuerpo de Ava parecería estar desnudo, es decir, el contorno remite a esa falta de recubrimiento. Aunemos a esto el hecho de que Nathan la diseñó a partir de los gustos sexuales de Caleb. El trato amable de Ava se suma al complejo de factores que infunde la fascinación en el chico.

La segunda sesión ya contiene variantes explícitas de dichos factores. Instantes previos, Nathan le sugiere a Caleb que investigue cómo se siente Ava con él. En la entrevista, Ava le presenta un dibujo abstracto y le pide su opinión. Caleb le indica que debería hacer algo más específico, por ejemplo, un objeto o una persona. Ava le pregunta qué tipo de objeto. Caleb le expresa que ella debe decidir. En este momento, el chico tiene el control de la situación y pretende seguir la instrucción que le había dado Nathan. De pronto, Ava cambia el procedimiento. Resulta relevante comentar que, antes de esta reacción, ambos permanecen sentados. Ava se pone de pie y le pregunta a Caleb si quiere ser su amigo. El joven responde afirmativamente. Ella le revela que está al tanto de su propósito, es decir, el de estudiarla. Para la robot, "esas no son las bases de una amistad". Esto hace girar la entrevista en torno a la vida de Caleb. Él, desconcertado, le pide que le indique

6 Para una amplia revisión de ese concepto, recomendamos Foucault (2005). 
por dónde empezar. Ava utiliza la misma respuesta que, minutos antes, Caleb le había ofrecido: "Es tu decisión".

Cabe recordar un par de factores importantes. Durante la primera sesión, Caleb se mantiene parado frente a Ava. Esta posición le otorga cierto poder sobre la robot; de hecho, él es quien formula la mayoría de las preguntas. En la sesión que seguimos, las cosas se invierten y ella toma el control; una muestra de eso es su posición vertical: la cámara enfoca cómo Caleb debe mirar hacia arriba para establecer contacto con Ava. Asimismo, desde esta segunda entrevista, ella ya exterioriza, marcada y constantemente, sentimientos, empatía, sonrisas; por un lado, proximidad y, por otro, autoridad.

El chico relata datos de su vida: dónde nació, dónde vive, su orfandad, su falta de pareja y hermanos, etcétera. Ella lo observa con detenimiento. Esta información es altamente determinante, ya que Ava la utilizará para posicionarse como una figura que llenará esos vacíos y, con mayor eficacia, envolverá al chico en su proyecto. Al término de la breve historia de Caleb, Ava, sentada y muy próxima al cristal, le pregunta si considera a Nathan un amigo. (Esta escena ya la habíamos abordado en el apartado anterior, pero desde otro punto de vista). La respuesta de Caleb es un tanto indecisa, pues lo conoció recientemente. Ava, entonces, produce un corte de energía para confesarle lo que piensa de Nathan. Esto significa que ella sabe que el chico no la delatará, pues, en la tercera sesión, le da a conocer a Caleb que tiene incluso la capacidad de analizar las microexpresiones faciales para determinar si una persona miente o no. Recordemos que ese mismo día, durante la cena, Caleb no le ofrece información alguna a Nathan acerca de lo sucedido durante la interrupción de electricidad.

En la tercera entrevista, Ava le muestra un nuevo dibujo a Caleb. Se trata de lo que puede ver ella a través de una ventana de su cuarto: un pequeño jardín interior. Caleb, confundido, le pregunta si ha salido de ahí alguna vez. Ava responde negativamente. Caleb continúa, quiere saber adónde iría si pudiera estar fuera del edificio. Ella escoge una intersección de tránsito peatonal para observar la vida de las personas. Con sutileza, ella propone la posibilidad de que él la acompañe. Para Caleb, eso representa una "cita". Sabemos que, en inglés, ese concepto puede connotar una posterior relación amorosa. A continuación, Ava le tiene preparada una sorpresa. Le dice al chico que cierre los ojos y se dirige al interior de su cuarto. Con evidente sensualidad, se coloca un vestido floreado, un suéter, calcetas y zapatos. Escoge una peluca de acuerdo con la fotografía de una modelo. Ya ataviada, regresa frente a un sorprendido Caleb; modela su nueva apariencia y le dice que así lucirá para su "cita". Vemos que este procedimiento le permite a Ava eliminar todo rastro robótico y, a pesar de cubrir su supuesta desnudez, su estrategia potencia el signo "humana" y, por lo tanto, se resemantiza a través de las connotaciones "inmediata", "sugestiva" y "sensual". La comparación con la modelo es un hecho que refuerza esto. 
En la primera parte de esta entrevista, antes de su transformación, y en la sección final de la misma, Ava permanece hincada. Esta posición tiene como objeto mostrar cierta sumisión y, al mismo tiempo, fragilidad y mayor cercanía sentimental.

Julia Kristeva (2000, p. 154) sigue a santo Tomás para señalar que el amor a uno mismo se extiende al amor al prójimo a partir del encuentro, la proximidad y la similitud. Esas tres nociones le permitirán a Caleb establecer paulatinamente una equivalencia de identidades entre él y Ava.

La sesión continúa. Ella expresa que sería "lindo" tener una cita. Abruptamente, le pregunta si es atractiva para él y le confiesa que puede leer sus microexpresiones (en los labios y ojos) que revelan ese sentimiento. El diálogo termina con las siguientes líneas:

Ava (sumamente sugerente, delicada y muy próxima al cristal): ¿Piensas en mí cuando no estamos juntos? [...] A veces, en la noche, me pregunto si me ves por las cámaras... Y espero que lo hagas [...]. Ahora, tus microexpresiones dicen que estás demasiado incómodo.

Caleb (desconcertado): No estoy muy seguro de que sean micro.

Ava: Yo no quiero hacerte sentir incómodo.

Esa tarde (Garland, 2015, 0:45:00), Ava, sabiendo que está rodeada de cámaras y que ha sembrado la tentación en Caleb, se desviste lenta y sensualmente. El chico, desde la pantalla de su cuarto, la observa con atención. Un acercamiento de la cámara a su cuello permite detectar sus vellos erizados, propios de una gran emoción.

La escena posterior (Garland, 2015, 0:46:05) gira en torno a una discusión acerca de la "sexualidad" de Ava. Caleb quiere saber si Nathan le dio una apariencia sexual a la robot. Su creador tiene un argumento psicológico: la dimensión sexual es un ingrediente esencial en cualquier nivel de conciencia humana o animal; por ello, no resultaría justo privar a la ginoide de esa oportunidad. Entonces, aparte de su aspecto atractivo, Ava posee una abertura, a manera de vagina, con una alta concentración de sensores. Esto podría representar la posibilidad de una experiencia de placer. Caleb, molesto, le cuestiona si diseñó a Ava para que le fuera atractiva.

La connotación "mirar una id-entidad" que habíamos determinado, ahora bajo las actuales funciones de simulación, nos presenta un vasto campo semántico en el que las nociones de sexualidad y atracción articulan el resto de las marcas connotativas de este apartado.

La simulación es tan profunda que Caleb, por su parte, duda de su propia identidad. La mañana del penúltimo día (Garland, 2015, 1:13:35), se mira en el espejo de su baño y 
se hace un corte en un brazo para confirmar su humanidad o, en todo caso, su esencia robótica?.

La separación que hicimos del prefijo id-fue con el objeto de subrayar la posibilidad de la derivación hacia la connotación "igualdad de identidad". La duda de Caleb invierte sus impresiones iniciales: ya no cree estar frente a una persona como él, sino que, tal vez, el encuentro sea entre robots. Así, la simulación trasciende los campos del conocimiento a los que está asociada, a saber, la inteligencia artificial y la robótica. Su molestia por el encierro de Ava y su amor por ella, además de su involucramiento en el plan de escape, sin tomar en cuenta la habilidad cognitiva de la ginoide, son los factores semánticos que desarrollan en Caleb esta nueva igualdad o confusión de identidades.

\section{LA FUNCIÓN DE LOS INTERTEXTOS}

Un intertexto es un fenómeno que se registra entre un texto fuente y un texto receptor o englobante (Genette, 1989, pp. 10-11). El primero cede parte o la totalidad de su materia significante al segundo. Como ambos están estructurados bajo procesos semiósicos y códigos específicos, habrá cierta resistencia en el traspaso. Por lo tanto, la materia significante que va de un lado al otro sufrirá determinadas deconstrucciones con el fin de ajustarse y, así, participar en la producción de sentido en el texto que la alojará.

En nuestro texto fílmico, encontramos dos intertextualidades ${ }^{8}$ centrales. Una de ellas ya resultaba demasiado evidente desde el inicio de nuestro análisis; se refiere a la obra A través del espejo y lo que Alicia encontró ahí, escrita por Lewis Carroll en 1872 (Carroll, 2001). La segunda, muy breve, corresponde a la canción Enola Gay (1980), del grupo británico de new wave OMD (Orchestral Manoeuvres in the Dark). El análisis de estos textos insertos nos permitirá, en adición, consolidar un par de nociones.

\section{El mundo a través del espejo}

Alicia quiere mostrarle a un gatito, hijo de su gata Dina, una casa muy peculiar que únicamente es posible ver mediante un espejo: “Fíjate, en primer lugar, está ese cuarto que

7 Ya nos habíamos referido a esta escena en el apartado anterior.

8 Detectamos tres más. Una pintura de Jackson Pollock (Garland, 2015, 0:48:45) que sirve como argumento a Nathan para diferenciar entre conciencia y no conciencia, por el grado de "automatismo" al que se sometía el artista a la hora de pintar (action painting). Un breve pasaje del filme Ghostbusters (0:22:18) que reafirma la noción de simulación. La teoría de la gramática generativa de Noam Chomsky (0:14:45) en la que se apoya Caleb para explicarle a Ava la capacidad innata de adquisición del lenguaje. Existe otro más (0:28:02), pero es Ava quien se encarga de reconocerlo y explicarlo. Se trata de la recopilación de notas de algunos cursos que dictara Ludwig Wittgenstein entre 1933 y 1935 que llevan el nombre de Blue and Brown books, similar a la compañía de Nathan. Los temas que trata ese texto colocan las bases de lo que, posteriormente, se llamaría el giro lingüístico. 
hay al otro lado del espejo, que se parece tanto a nuestro propio salón, solo que las cosas están al revés de como están aquí" (Carroll, 2001, p. 243). La niña, como parte de un juego, invita al gato a entrar en ese lugar: "ilmagínate que el cristal se ablandara hasta convertirse en una suerte de cendal de manera que pudiéramos franquearlo con toda facilidad!" (p. 244). Su deseo se cumple: "Un instante después Alicia había pasado a través del cristal y a continuación se había dejado caer en el salón de la Casa del Espejo" (p. 244). En las líneas iniciales de la diégesis, la voz narrativa nos cuenta que Alicia, "acurrucada en una poltrona, hablaba consigo misma entre dormida y despierta" (p. 239). Las referencias contextuales al ambiente lúdico en el que ella y el gato "entran" en la Casa del Espejo y la que corresponde al onírico (obtenida de la voz narrativa) nos desvelan una microsemiótica dicotómica, es decir, la identidad de Alicia se encuentra, al mismo tiempo, entre unas circunstancias que pertenecen a la fantasía y a la realidad. La evanescente y confusa línea divisoria entre una y otra está marcada por el signo espejo. En los primeros momentos, la similitud entre ambos lados no le causa mayor sorpresa a la niña; no es sino hasta cuando observa bien algunos objetos que, con asombro, se percata de que tienen vida.

En nuestro texto, la microsemiótica se deconstruye inicialmente en la forma humano vs. no humano. El polo humano modeliza, obviamente, la identidad de un Caleb confuso. Debido a que el chico entra en el experimento con la certeza que le otorga el test de Turing de que enfrentará a un robot, entonces, Ava debe vincularse a la noción no humano. De alguna manera, esas mismas nociones tienen como correlato otra microsemiótica: realidad vs. no realidad. Pensemos que los objetos fantásticos que sorprenden a Alicia guardan un paralelismo con la máquina que, frente a Caleb, pretende poseer conciencia. Posteriormente y con base en el chico, la microsemiótica rompe o disuelve la línea divisoria y deviene, dentro de diferentes momentos, en una doble unidad semántica: id-entidad humana o id-entidad robótica. Si observamos bien, al final, ambas se confunden a raíz de la marca connotativa conciencia vinculada a Ava (y todas sus derivaciones sexuales, seductoras, sentimentales, cognitivas, en fin).

El test de Turing se basa en que una persona, sin poder saber con quién interactúa, debe determinar si lo hace con un humano o con una máquina. La capacidad de expresar conciencia es el factor decisivo en este caso. En nuestra pareja, ya no resulta pertinente privar a uno o a la otra de esta facultad, por lo tanto, tampoco la de simular. Recordemos que Caleb duda de ser un humano y, al entrar en el juego falaz de Ava, no es honesto con Nathan. En este sentido, la acción especular que distingue al texto de Carroll se extiende hasta participar junto con la noción de simulación que ya habíamos notado. El paso de un mundo a otro que logra Ava es inverso al de Alicia, por ello es que la robot debe apropiarse de una identidad más humana y real; es decir, se disfraza con vestigios de las otras ginoides (01:34:20) para, posteriormente, salir y confundirse entre la gente. Aquellas otras máquinas se hallan desactivadas dentro de unas cajas cuya superficie frontal es un espejo. El encuentro de Ava con ellas exhibe el múltiple efecto reflector 
que pretende generar una diferencia identitaria, esto es, más humana en Ava que en las otras. El estado activo de Ava nos propone una nueva microsemiótica diferenciadora: vida vs. no vida. Es claro que ambos polos provienen de unas circunstancias producidas por el reflejo de los espejos, lo que, una vez más, nos conduce a la noción de simulación.

\section{Transgresión}

El segundo día por la mañana, Caleb escucha en un pequeño reproductor de música la canción Enola Gay (1980). El nombre de esta pieza se refiere al avión estadounidense que transportó la primera bomba atómica causante de la destrucción de Hiroshima a finales de la Segunda Guerra Mundial. Veamos las tres primeras estrofas?.

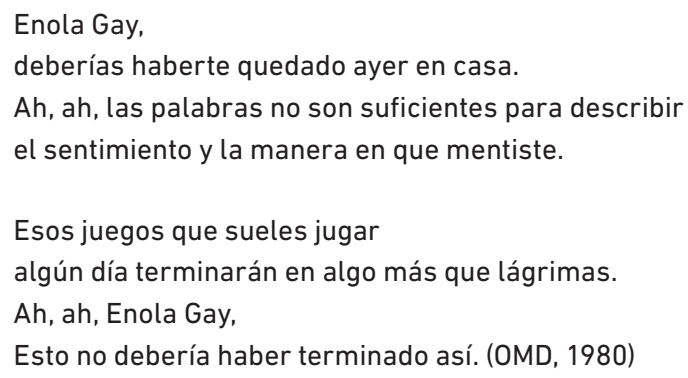

Existe una idea que subyace y, además, sirve como nexo para las líneas anteriores. Se trata de la tragedia que produjo ese primer experimento atómico sobre Japón y que, de acuerdo con la segunda estrofa, se extendería a lo largo de décadas, aunque fuera tan solo como amenaza ${ }^{10}$. El final de nuestro objeto de estudio deja claramente explícita esa tragedia cuando Ava mata a Nathan, su creador, para fugarse; se olvida de Caleb, su medio de escape, y se funde en la vida humana. En ambos textos, el filme y la canción, esa tragedia es relativa a la larga carrera científico-tecnológica distintiva del género humano que, paradójicamente, apunta hacia la anulación de esa misma humanidad.

En las últimas escenas, Ava camina por un amplio andador de una ciudad, tal como ella se lo había anticipado a Caleb; se halla en un espacio que le permite observar a las personas. Su sombra, al avanzar, se cruza con la del resto de los viandantes. Todo culmina con el reflejo de Ava en el cristal de un aparador.

Si tomamos tragedia como un nuevo fundamento que configura a Ava como signo, encontramos en Nathan la noción de transgresión. Para explicar esto, es preciso referirnos a otros textos. El primero consiste en un libro de la Biblia.

9 Hemos hecho la traducción del inglés tratando de respetar el sentido original.

10 Nos referimos a la inauguración de una nueva guerra, la Guerra Fría, y a unas nuevas formas de vida y de conflictos internacionales. 
La tradición judeocristiana coloca a Dios como ser supremo y creador del ser humano. En este sentido, esta criatura se encuentra subordinada a los deseos de aquella deidad. Queda claro, pues, que el ser humano cometería una transgresión (pecado) si se situara al mismo nivel o por encima de esa figura suprahumana. Solo para ilustrar lo anterior, recurriremos al siguiente pasaje del Génesis en el que la serpiente tienta a Adán y a Eva para que coman del "árbol de la sabiduría" o "árbol de ciencia del bien y del mal". El animal les dice: "Mas sabe Dios que el día que comiereis de él, serán abiertos vuestros ojos, y seréis como dioses sabiendo el bien y el mal" (1:5). La desobediencia de la pareja edénica sufre un cambio semántico posterior: "El pecado original, fuente de la desdicha humana, que figura en el Génesis como pecado de orgullo y un desafío del hombre hacia Dios, se convierte en la Edad Media en un pecado sexual" (Le Goff y Truong, 2005, pp. 12-13). Detrás de esa acción infractora, subyace también una actitud de curiosidad y un deseo de saber (p. 45), que es lo mismo que adelanta la serpiente.

Pongamos, además, atención en que el nombre de la robot es muy similar al de Eva11. El paralelismo no solo es fonético, sino semántico. Eva, como primera mujer, se encuentra inmersa en un tiempo y en un entorno germinales. Ella, junto con su pareja, aprende de lo que la rodea. Algo similar sucede con Ava: es la robot quien, después de seis días de aprendizaje (los mismos que le llevan a Dios crear el universo), sale al mundo verdadero en el séptimo, no para padecer, sino para continuar con la expansión de su inteligencia y mezclarse con la humanidad. La reflexión de su imagen en el gran ventanal del aparador (Garland, 2015, 1:42:12) indica esa especie de ascenso. Antes de abandonar la casa, como ya mencionamos, se coloca la piel sintética de las otras ginoides, se viste y se pone una peluca rubia. Su figura que muestra el cristal del aparador hace alusión a la evolución y la simulación, que le permiten pasar por una entidad humana.

Después de la primera sesión, Caleb (Garland, 2015, 0:11:10) se refiere a Nathan como un dios: "Si pudiste crear una máquina consciente, esta no es la historia del hombre; es la historia de los dioses". Este es, pues, el acto de "orgullo" y de "sabiduría" que mueve a Nathan a colocarse como un ser dador de vida o un demiurgo. Su transgresión no termina aquí. Nos referimos a las tres leyes de la robótica, propuestas por Isaac Asimov en un cuento corto. Estas reglas se han abordado, incluso, fuera del ámbito de la literatura ${ }^{12}$.

Dos científicos, Gregory Powell y Mike Donovan, se encuentran cumpliendo una misión en una mina del planeta Mercurio. Los acompaña Speedy (SPD-13), entre otros robots. Este pequeño relato sirve como pretexto para la formulación de dichas leyes en boca de Powell. La primera regla es la que nos interesa: "Una, un robot no puede hacer

11 Los nombres bíblicos de Nathan y Caleb también representan una referencia intertextual.

12 La Comisión de Asuntos Jurídicos del Parlamento Europeo ha ampliado esas leyes de tres a seis. Recomendamos revisar su documento en https://www.europarl.europa.eu/RegData/etudes/ STUD/2016/571379/IPOL_STU(2016)571379_EN.pdf 
daño a un ser humano, o, por medio de la inacción, permitir que un ser humano sea lastimado" (Asimov, 1990, p. 12).

En un par de escenas más, localizamos otros intertextos que refuerzan las nociones que estamos siguiendo. El primero (Garland, 2015, 1:06:37) sucede durante una plática entre Nathan y Caleb en el campo. Nathan le explica al chico la manera en que perfecciona a las robots (esto ya lo habíamos comentado en el cuarto apartado). Caleb, indignado porque sabe que Ava sufrirá una irremediable desconexión posterior, recita las palabras que Robert Oppenheimer (científico participante en el proyecto de la bomba atómica) tomara del texto sagrado hindú, el Bhagavad-gītā: "Me convertí en la muerte, el destructor de mundos". Una vez en la casa, Nathan, quien ha bebido demasiado, continúa con un pasaje del mismo libro sagrado que le sirve como un argumento justificante contra la acusación anterior de Caleb.

Nathan: En la batalla, en el bosque, en el precipicio de las montañas, en el vasto y oscuro océano, en el sueño, en la confusión, en la profunda humillación, las buenas obras que un hombre ha hecho antes lo defienden, las buenas obras que un hombre ha hecho antes lo defienden, las buenas obras que un hombre ha hecho antes lo defienden... Es lo que es... Es como Prometeo, Caleb.

Finalmente, el título del filme (elemento paratextual) es parte de una frase griega usada en el ambiente teatral clásico: deus ex machina ("dios [que baja] de la máquina") ${ }^{13}$. En una obra dramática, cuando la trama se complicaba y, al parecer, no había solución, existía un artificio técnico para remediarla: un dios, mediante un mecanismo similar al de una polea, bajaba al escenario y ponía todo en orden. Dicha locución, apocopada, pasa a nuestro texto. La deconstrucción elimina al agente de la acción (deus) y le confiere el papel principal a la máquina: "desde la máquina". Nathan, un nuevo Prometeo, les roba el fuego del conocimiento a los dioses para entregárselo a la máquina. Notemos, en lo dicho en este subapartado, la bifurcación de la noción de transgresión: la propia de Nathan y la que realiza Ava.

La función transgresora de Nathan tiene como correlato la de "creador". En esta última, ese hombre pretende cruzar el umbral entre lo humano y lo divino. Por su parte, Ava, al pasar por los procesos de aprendizaje y de humanización, también atraviesa un umbral para abandonar su identidad robótica. En ambos recorridos de lectura, aparecen vinculados entre sí los signos hegemónicos simulación y transgresión.

13 En este caso, no estamos hablando, propiamente, de un intertexto, sino de una interdiscursividad. 


\section{TRANSHUMANISMO Y BIOMEJORAMIENTO MORAL}

A partir de algunos de los signos hegemónicos que hemos encontrado hasta el momento, accederemos a las circunstancias sociohistóricas que rodean la producción del filme.

Desde que el primer simio o protohumano tomara en sus manos, digamos, un palo para hurgar en un nido de hormigas, se colocan los primeros cimientos de la larga escalada evolucionista, fuertemente ligada a la científico-tecnológica, de la humanidad. Esta hipótesis ${ }^{14}$ tiene como punto final el desplazamiento del ser humano por el robot.

Tomaremos las dos décadas que van de 1980 al 2000 como los antecedentes científicos más influyentes para nuestro filme. La primera se distingue por ciertas investigaciones genéticas; su principal objetivo reside en encontrar la secuencia completa del ADN humano, lo cual fue posible en el 2003. Ya en 1984 y 1990, varias naciones habían confluido en el megaproyecto Genoma Humano. Un resultado adyacente se dio en 1997, con la culminación del experimento de clonación de la oveja Dolly. El segundo período recibió el nombre de "década del cerebro"; algunas de sus metas fueron: (a) la búsqueda de la cura para diferentes enfermedades, trastornos y discapacidades que se originan en o afectan al sistema nervioso; (b) conocer el funcionamiento del cerebro; y (c) saber por qué las personas abusan del consumo de las drogas (Martín-Rodríguez et al., 2004, pp. 133-134). Hay, empero, dos factores que llaman la atención: (a) la iniciativa urgente del gobierno de George Bush padre, en particular, para dar inicio a este esquema en coordinación con otras naciones; y (b) la creación de nuevos fármacos para aliviar los diferentes problemas del sistema nervioso (pp. 134, 157-158). Veamos la participación de los factores político y comercial en todo esto.

Tras los logros y el entusiasmo innegables en ambos esfuerzos, debemos poner atención en la manifestación

[...] de muchas inquietudes sobre los alcances y los posibles límites éticos del uso y las aplicaciones del conocimiento producido por las neurociencias [...]. Los conocimientos actuales de las neurociencias generaron al menos los siguientes cuatro tipos de problemas éticos: (1) los derivados de los estudios por imagen de la activación de regiones cerebrales; (2) el uso de drogas para incrementar la capacidad mental; (3) la posibilidad de identificar y modificar la personalidad de los individuos; y (4) las posibles consecuencias del conocimiento íntimo, en términos neurobiológicos, de la conciencia y del yo. (Tapia, 2008, p. 188)

Sería ingenuo suponer la ausencia de ideología (de cualquier tipo) en el ejercicio científico. Verón (1998) apunta al respecto: “Hablar de 'ideológico' es tratar de hablar de la naturaleza productiva de todo fenómeno de sentido", como lo es la ciencia (p. 25; el resaltado es textual).

14 Hipótesis que sigue las propias de Eco (1999, p. 28-29) y la que da inicio al filme de Stanley Kubrick de 1968, 2001: Una odisea del espacio. 
De acuerdo con el psicoanalista Gérard Wajcman (2011), hacer transparente el funcionamiento cerebral va más allá de un interés genuino:

la captación de imágenes en medicina tiene su máquina de vanguardia en Saclay, cerca de París. Se llama NeuroSpin.

Proyecto gigantesco, ciclópeo, NeuroSpin es una máquina IRM (imágenes por resonancia magnética) de una potencia incomparable. [...]

Instrumento para ver nuestros pensamientos, la resonancia magnética es una técnica dirigida a conocer el secreto de estos. En resumen, NeuroSpin es una máquina destinada a sonsacar lo íntimo, la máquina que este mundo esperaba. En la práctica, esto significa que se irá a mirar cuáles son las áreas del cerebro que se encienden cuando sucede tal o cual cosa, gracias a lo cual sin duda se podrá determinar exactamente el color que hay que ponerle al contenedor de lavandina para que den más ganas aún de comprarlo. (pp. 27 y 29; el resaltado es textual)

El transhumanismo y el biomejoramiento moral representan un punto álgido en esta carrera cientificista.

El transhumanismo cuenta con una página en la red ${ }^{15}$. Esta organización se enfoca en fomentar, "con bases éticas", "la expansión de las capacidades humanas" mediante el aprovechamiento de los avances tecnológicos. La promoción se logra, principalmente, a través de conferencias alrededor del mundo y de la publicación de una revista ( $H$ + Magazine). Su declaración, redactada en 1998, puede resumirse en los siguientes aspectos: (a) superación del envejecimiento, de las deficiencias cognitivas (mejoramiento de la memoria y la concentración, por ejemplo), del sufrimiento involuntario y del confinamiento a la Tierra; (b) convencimiento de que existen escenarios posibles que pueden conducir a condiciones humanas "maravillosas y valiosas"; (c) uso de tecnologías de elección reproductiva; y (d) ver la criogénesis como una posibilidad para evitar la muerte ${ }^{16}$.

En principio, pensemos en quiénes tendrán acceso a esos beneficios científicotecnológicos tan especiales. Esto ya nos pone frente a una fuerte división darwinista social: la evolución tecnológica, por sus altos costos, resulta una herramienta discriminatoria. En consecuencia, el valor ético del proyecto puede verse en graves problemas. Otro aspecto que atañe al factor ético es el de considerar "modelizable" y "robotizable" el "obsoleto" cuerpo humano natural; es decir, hay un rechazo despectivo ("superación") hacia su composición biológica y el entorno terrestre ("confinamiento"); por lo tanto, se

15 Véase la página web: https://humanityplus.org/. Es importante indicar que esta organización se anuncia como exenta de fines de lucro. No obstante, es una plataforma ideal para presentar a personas dedicadas a la investigación de propuestas novedosas en materia de genética y criogénesis humanas.

16 Para la consulta completa de la declaración, recomendamos visitar la página https://humanityplus. org/philosophy/transhumanist-declaration/ 
impone la alteración genética en busca de la perfección y la exploración de otros mundos para reiniciar una nueva vida. Como se trata de modificar también la mente, el repudio afecta las prácticas culturales (particularmente morales) del ser humano: "Se puede entrever que la biotecnología y la neurotecnología de carácter eugenésico han tomado impulso a partir de la imagen moderna de la humanidad, que se muestra como algo 'obsoleto' y extremadamente maleable, susceptible de mejora técnica" (Linares Salgado, 2018, p. 18).

En cuanto a la modificación de determinadas actitudes humanas cuestionables, el biomejoramiento moral es la otra alternativa. Los filósofos Ingmar Persson y Julian Savulescu defienden esta posibilidad. En concreto, ellos encuentran altamente deficientes las instituciones judiciales y educativas actuales frente al combate de los problemas de violencia, bélicos, ecológicos, de desigualdades sociales, etcétera, por los que cruza la humanidad; por lo tanto, es "urgente" el biomejoramiento moral. En este caso, nuestras preguntas son estas: ¿quiénes deben someterse a esos tratamientos?, ¿a quiénes beneficia una sociedad altamente "ética"?, ¿no es esto la otra cara de la propuesta eugenésica que no atiende el transhumanismo, es decir, el sector laboral?

Con el lema "Claro que debemos jugar a ser Dios", Savulescu difunde en varios foros internacionales la idea de lograr, mediante la biotecnología, la "selección de mejores niños" si se les administra Ritalin o (Ritalina) (De Jeorge, 2019). Este fármaco (metilfenidato) se usa para niños hiperactivos, con déficit de atención o personas que sufren narcolepsia (somnolencia extrema). Es altamente adictivo y va acompañado de graves efectos secundarios, si lo consumen personas no diagnosticadas con déficit de atención o hiperactividad y, obviamente, sin un seguimiento por parte de un profesional (Fernández Vallejo, 2009; Franco Netto et al., 2018). El origen de esta droga se remonta a los inicios de la década de los cincuenta del siglo pasado:

La Guerra Fría llevó a que el sistema educativo se transformara radicalmente. EE. UU. se encontraba en competición con la Unión Soviética en todas la áreas; por consiguiente, se requería un sistema más rígido, estandarizado, donde se implementaran los objetivos fijados a nivel del gobierno federal y donde se llevara a cabo un fuerte escrutinio y una mayor exigencia a los alumnos para formar mentes brillantes a nivel científico (en áreas como aritmética, economía, lenguas e ingeniería). [...] Todo esto se convirtió en un propósito nacional. (Londoño Paredes, 2017, p. 486)

Nuestra preocupación no reside en el mejoramiento, físico y/o moral, en sí del ser humano. Después de todo, eso siempre ha sido una constante: la búsqueda de mejores alimentos, mejores remedios o medicinas, prótesis, en fin. La objeción está constituida por los factores comerciales y políticos que pretenden perseguir "buenas acciones". Aparte de los objetivos trazados por las dos décadas mencionadas, existe, como lo hemos visto, la voluntad de conocer, manipular, limitar y, por lo tanto, vigilar más de cerca a la 
sociedad; esto representa la materialización de una de las aportaciones centrales de Michel Foucault, a saber, la microfísica del poder. Por el lado de la ideología de mercado, un ser humano, más que ético, sensible a las propuestas de consumo y, al mismo tiempo, cada vez menos errático y más hábil dentro de su espacio de trabajo.

Según Vaccari (2013), el transhumanismo es un movimiento que se origina a partir de los presupuestos económicos sociales del mundo anglosajón, por lo que muchos de sus tópicos centrales reflejan, en algún sentido, los ideales de libre mercado, así como una ética utilitarista tan defendida en países como los Estados Unidos. Ya sea este el caso o no, lo que no se puede negar es que el ideal de progreso científico y mejora tecnológico-humana subyace en la mayoría de las disciplinas y posturas desarrollistas actuales. No en vano, cada vez con más frecuencia los países desarrollados, así como los que no lo son, invierten en la investigación tecnocientífica, específicamente en lo relacionado con la innovación y el diseño (I+D), como formas de crear progreso económico y, en algunos países, avance social. (Piedra Alegría, 2017, p. 490)

\section{CONCLUSIONES}

Ava, como signo fundamental del filme, lleva a cabo varias funciones. Como todo signo, estará siempre en lugar de algo más. Al final de nuestro recorrido, esta capacidad sustitutiva la desvela como una estrategia textual que transcribe ciertos fenómenos sociales. Tres connotaciones hegemónicas nos permitieron el arribo a ese nivel extratextual: simulación, transgresión y vigilancia. La alta imbricación entre ellas logra evidenciar consecuencias éticas e ideológicas. Esta interrelación explica la solidaridad sígnica mencionada en el segundo apartado.

Asimismo, nuestro texto cinematográfico, como elemento cultural, media entre la realidad y la ficción a través de códigos de simbolización: recoge, modeliza y visibiliza el fenómeno de la robotización del ser humano. Ava es, de alguna manera, una alegoría que sigue la línea trazada por la Maschinenmensch, robot femenino de Metrópolis (1927).

El riesgo del engarce entre las ideologías de poder y de seducción mercantil con el campo de la ciencia y la tecnología ha resultado, paulatinamente, en un mundo vigilado por un panóptico menos perceptible, pero más efectivo.

Podemos decir, entonces, que el abordar los textos desde una postura transdisciplinaria permite obtener una perspectiva analítica más amplia. La dimensión ficcional del filme no representa una limitante para establecer una relación entre este y determinadas problemáticas sociales de su tiempo. 


\section{REFERENCIAS}

Asimov, I. (1990). Visiones de robot. Debolsillo.

Carroll, L. (2001). A través del espejo y lo que Alicia encontró ahí. Cátedra.

Cros, E. (1986). Literatura, ideología y sociedad. Gredos.

Cros, E. (2002). El sujeto cultural. Sociocrítica y psicoanálisis. CERS.

De Jeorge, J. (18 de noviembre del 2019). Filósofo de la Universidad de Oxford defiende como una "obligación moral" el uso de la biotecnología para seleccionar los mejores niños [entrevista a Julian Savulescu]. El Nuevo Mundo. https://www. periodicoelnuevomundo.com/2019/11/filosofo-de-la-universidad-de-oxford. html

Eco, U. (1999). La estructura ausente. Lumen.

Eco, U. (2000). Tratado de semiótica general. Lumen.

Fernández Vallejo, R. (2009). Impacto corporal de los medicamentos para el trastorno por déficit de atención con hiperactividad en los niños. Revista Electrónica de Psicología Iztacala, 2(12), 54-73. https://www.iztacala.unam.mx/carreras/psicologia/psiclin/vol12num2/Vol12No2Art4.pdf

Foucault, M. (2005). Vigilar y castigar. Nacimiento de la prisión. Siglo XXI.

Franco Netto, R. 0-R., De Almeida-Rodrigues Franco Netto, J., Zacarias-da Silva Junior, N., Silva, S., Ferreira-Aguero, M. A., Coronel-de Bobadilla, B., y Pifferrer, A. (2018). Incidencia del uso no prescrito del metilfenidato entre estudiantes de medicina. Revista del Instituto de Medicina Tropical, 13(1), 16-22. https://doi.org/10.18004/ imt/201813117-23

García-Sedano, M. (2019). La rebelión de las máquinas. Arte, singularidad tecnológica y ciencia ficción. Arte, Individuo y Sociedad, 31(3), 643-658. https://doi.org/10.5209/ aris.61598

Garland, A. (Director). (2015). Ex-machina [película]. DNA Films.

Genette, G. (1989). Palimpsestos. La literatura en segundo grado. Taurus.

Kristeva, J. (2000). Historias de amor. Siglo xxI.

Le Goff, J., y Truong, N. (2005). Una historia del cuerpo en la Edad Media. Paidós.

Linares Salgado, J. E. (2018). Hacia una crítica neuroética del mejoramiento moral. En P. E. García Ruiz, R. E. López García y P. E. Santamaría Cruces (Coords.), Ética y neurociencias. La naturalización de la filosofía moral (pp. 13-31). Universidad Nacional Autónoma de México. 
Londoño Paredes, D. E. (2017). El trastorno por déficit de atención con hiperactividad: una mirada socio-cultural. Revista de la Asociación Española de Neuropsiquiatría, 37(132), 477-496. http://scielo.isciii.es/pdf/neuropsiq/v37n132/0211-5735raen-37-132-0477.pdf

Martín-Rodríguez, J. F., Cardoso-Pereira, N., Bonifácio, V., y Barroso y Martín, J. M. (2004). La década del cerebro (1990-2000): algunas aportaciones. Revista Española de Neuropsicología, 6(3-4), 131-170. https://idus.us.es/bitstream/ handle/11441/51153/La\%20d\%c3\%a9cada\%20del\%20cerebro.pdf?se quence $=1$ \&isAllowed $=\mathrm{y}$

Orchestral Manoeuvres in the Dark (OMD). (1980). Enola Gay (canción). En Enola Gay. Dindisc.

Peirce, C. S. (1994). The collected papers of Charles Sanders Peirce. Harvard University Press.

Piedra Alegría, J. (2017). Transhumanismo: hacia un nuevo cuerpo. Daimon Revista Internacional de Filosofía, Suplemento 5(2016), 489-495. https://doi.org/10.6018/ daimon/270011

Tapia, R. (2008). Neuroética. En R. Pérez Tamayo, R. Lisker y R. Tapia (Comps.), La construcción de la bioética (pp. 185-198). Fondo de Cultura Económica.

Verón, E. (1998). La semiosis social. Fragmento de una teoría de la discursividad. Gedisa.

Wajcman, G. (2011). El ojo absoluto. Manantial. 